\title{
TURISMO E MEIO AMBIENTE NA AMAZÔNIA Perspectivas Econômicas do Turismo Ecológico
}

\author{
Antonio Evaldo COMUNE*
}

\begin{abstract}
RESUMO: A região da Amazônia, no Brasil, experimentou, nas últimas décadas, uma grande transformação como resultado da intervenção pública e privada. O setor de turismo que já contribuiu de maneira decisiva para o crescimento da região, pode desempenhar. no futuro, um papel ainda mais importante. principalmente se a opção pelo turismo ecológico for incentivada. $\mathrm{O}$ impacto direto desta atividade. segundo estimativas realizadas tomando-se como base o ano de 1991. atinge cifras na faixa de 100 a 150 milhōes de dólares/ano, dependendo da hipótese que se adota quanto à motivaçăo do turismo doméstico. Este é apenas o impacto direto para o turismo referente à cidade de Manaus. É preciso contabilizar, ainda, a parte concernente às demais regiōes da Amazônia, além dos outros efeitos multiplicadores que se verificam no resto da economia. Constata-se, portanto, que a exploração do turismo ecológico representa uma excelente alternativa para o desenvolvimento da região amazônica, oportunidade esta que deve ser explorada de maneira adequada para não agredir o frágil ecossistema da região.
\end{abstract}

UNITERMOS: Turismo: Amazônia; ecologia; meio ambiente: economia. Turismo ecológico: impacto econômico. Economia: turismo; turismo ecologico.

ABSTRACT: During the last decades the Amazon region has expericnced a great change as a result of public and private actions. The tourism, which has strongly contributed for the region growth, can, in the near futture, play a role even more important, mainly if the enonnous potential of the "ecological tourism" is deeply exploited. The direct impact of this activiti" is actually valuated in 100 to 150 million dollars-year (vear-basis:1991). This represents only the direct impact in Manaus. One must add to this total the impacts in all Amazon region and the other values resulting fiom the indirect effects in the rest of the economv. These values are related to the sectorial multiplier of tourism activity. In this way", the "ecological tourism " represents an excellent option for the development of Amazon region, an opportunity that has to be appropriately exploited in order to protect the enviromment.

(*) Professor Assistente Doutor do Depto. de Economia da Faculdade de Economia e Adıninistração da Universidade de São Paulo.

End. para corresp.: FEA-USP - Cidade Universitária - Av. Prof. Luciano Gualberto. 908 - CEP (05508 - São Paulo - SP - Brasil. 
KEY WORDS: Tourism: Amazøn region: ecology: environment: economy. Ecological tourism: economic impact. Economy: tourism: ecological tourism.

\section{INTRODUÇÃO}

A partir do final da década de 1960, a região da Amazônia, que compreende cerca de $60 \%$ do território nacional e que se constituía, até hem pouco tempo, em um enorme vazio demográfico e econômico, à exceção de raros pólos como Manaus e Belém, entrou cm um processo de grande transformação em função de uma série de iniciativas do governo federal. Essa regiāo constitui-se, atualmente, em conjunto com a regiāo centro-oeste, na nova fronteira econômica do Brasil.

As iniciativas governamentais se consubstanciaram nos sucessivos planos que vigoraram a partir da década de 1970: Metas e Bases para a Ação do Governo, 1970-73; I, II, III Planos Nacionais de Desenvolvimento, 1972-85.

Com diferentes ênfases, os objetivos de promover a integraçāo nacional e reduzir os desequilíbrios regionais estiveram presentes nestes planos. Mahar ${ }^{1}$ desenvolve, especificamente para o caso da regiāo da amazônia, a análise retrospectiva das políticas regionais contidas nesses planos.

A intervenção nessa regiāo não foi ainda, em seu conjunto, devidamente avaliada do ponto de vista econômico, quer pela iniciativa privada, quer pelos órgãos governamentais, de modo que não se encontra claramente difundida a idéia da enorme importância das mudanças que a regiāo experimentou nas últimas décadas. Estima-se que o Produto Interno Bruto anual - PIB - da regiāo da Amazônia Legal atingiu, no final da presente década, cerca de US\$ 15 bilhões, incluídos aí a parcela produzida nos Estados de Mato Grosso, Tocantins e Maranhão. O PIB estimado somente para a parte da Amazônia não compreeendida por estes Estados já teria atingido a cifra de USS 9,5 bilhões, conforme Benchimol'- Outras informações sobre o impacto econômico e social do desenvolvimento recente da Amazônia podem ser encontradas no I Plano de Desenvolvimento da Amazônia, claborado pelo Minter-Sudam e no trabalho de Comunet.

O setor de turismo contribuiu, substancialmente, para a transformação da regiāo, mas é inegável que esta contribuição) poderia ser ainda ampliada, principalmente se fosse explorada mais intensamente a opção do turismo ecológico. Este tipo de turismo é assim denomina- do porque está baseado) nas atraçoes proporcionadas pelo meio ambiente, pelos atrativos da f̂lora, da fauna, dos rios, enfim, da natureza. Representa uma grande alternativa econômica para a regiảo amazônica, onde estes recursos são abundantes. No conjunto, tais airações constituem-se num produto turístico único no mundo, no qual praticamente nảo mais existem recantos naturais intocados. Entretanto, a exploração do potencial deve ser realizada de modo racionaí e planiejado. com pousadas e acampamentos nas florestas dos parques e reservas da regiāo, para que danos irreparáveis aos frágeis ecossisiemas da regiāo sejam evitados

\section{POTENCIAL DO TURISMO NO BRASIL E NA AMAZÔNIA}

A exploração píancjada do turismo como atividade econômica no Brasil é bastante recente. Pode-se estabelecer o início da década de 1960 como ponto de partida para as atividades de turismo no País, enquanto que em outras partes do mundo este já era explorado, de forma econômica racional, desde a década de 1930.

- crescimento desta atividade a nível mundial foi tão espanısoso que atualmente o turismo já é considerado uma das méhores oportunidades de negócios, particularmente para alguns países e regiōes, tánto pelos governos como pela iniciativa privada. De fato, os impactos econômicos e sociais que esta atividade pode provocar nas regiōes em que se desenvolve são bastante significativos, chegando a representar expressivas proporções na participação do produto inıerno gerado è a empregar grande parcela da população economicamentc ativa nestas partes.

No Brasil, a participaçāo do setor de turismo no Prociuto Interno Bruto é ainda muito baixa, atingindo, na média do País, valores menores que $1 \%$ daquele agregado macroeconômico. É evidente que para certas regiñes a proporção pode diferir, mas a fraca proporçào acima apenas reforça a observação) de que o setor é ainda incipiente no Brasil, principalmente ao se considerar a enorme potencialidade de aproveitament() dos recursos naturais ainda não explorados.

Em nível mundial, a demanda por turismo é crescenie, situando-se, alualmente, em torno de 600 milhöes de clientes/ano. A motivação da demanda passou por uma evolução ao longo das últimas décadas, sendo, no momento, muito valorizados os elementos relacionados ao meio ambiente, justamente aqueles que o Brasil, e em particular a Amazônia, apresenta claras vantagens comparativas. Aliás, hoje a 
participação mundial do Brasil na renda total gerada pelo turismo não atinge $2 \%$, sendo também baixa a participação da Amazônia no total do País devido a diversos fatores analisados mais adiante.

O turismo constitui, portanto, para a região da Amazônia, uma fonte potencial de riqueza, que muito pode contribuir para o seu desenvolvimento. Tendo em vista suas peculiaridades, a exploração do turismo necessitará principalmente da participação de fatores externos à região, sobretudo de recursos de capital, e também de recursos humanos para planejar, organizar e estruturar a atividade.

\section{OFERTA E DEMANDA DE TURISMO NA AMAZÔNIA}

Os elementos que compõem a oferta do setor são representados pelos equipamentos, pela infra-estrutura e pelos serviços destinados a atender as necessidades dos turistas que procuram a região.

$\mathrm{O}$ ponto crucial no concernente à oferta é a disponibilidade de quartos e acomodações em hotéis e similares para os viajantes, equipamentos estes que precisam atender diferentes exigências e níveis de renda. Embora esteja em expansão, é preciso reconhecer que a oferta de hotéis e acomodações na região é bastante limitada, situando-se muito aquém da demanda real e potencial.

Nos últimos anos tem-se observado a expansão da oferta de acomodações direcionada sobretudo para o atendimento da demanda por turismo ecológico, o que tem resultado na construção de "alojamentos na selva", que podem, em alguns casos, ser bem sofisticados em termos de serviços e instalações. Também neste caso, a procura é maior que a disponibilidade, constituindo-se em um fator limitante à expansão do setor.

No que diz respeito aos outros elementos da oferta, a situação na região é deficitária, excluindo-se, evidentemente, a oferta de atrações, cuja contribuição é propiciada pelos elementos do meio ambiente e beleza natural da região, além do patrimônio cultural, monumentos, edifícios públicos, museus etc., que atendem aos interesses dos turistas. Todavia, no que tange à disponibilidade de restaurantes e lazer noi urno a oferta é insuficiente, como também na questão referente ao ıbastecimento, caracterizado pelo alto nível dos preços dos gêneros de primeira necessidade e industriais, sobre os quais incide elevado custo de transporte em decorrência da grande distância e isolamento da regiāo.

Na questão relativa aos transportes, observa-se que a deficiência de infra-estrutura rodoviária que limita muito o setor de turismo é, em parte, compensada pelo bom atendimento do transporte acroviário c pelo abundante transporte fluvial. Mas, mesmo nestes dois casos os fatores restritivos ao setor sāo os altos custos do transporte aéreo, por um lado, e o não atendimento de demandas específicas de transporte por barcos, por outro, o que prejudica sobremancira um completo atendimento.

No que diz respeito à demanda por turismo na região da Amazônia, as informações analisadas estão circunscritas ao estado do Amazonas e a sua capital, Manaus, que apresenta a maior participaçāo no total da regiāo, e que estāo contidas no Plano Estadual de Turismo e no Boletim de Indicadores Econômicos", ambos editados pela Secretaria da Indústria, Comércio e Turismo do Estado do Amazonas. As cifras da Tabela a seguir constituem valores aproximados que foram arredondados para facilitar a apresentação, mas que permitem no entanto, uma perfeita idéia da situação da demanda interna e externa.

TABELA - Hóspedes brasileiros e estrangeiros nos estabelecimentos classificados

\begin{tabular}{|c|c|c|c|c|c|}
\hline \multirow{2}{*}{ ANO } & \multicolumn{2}{|c|}{ Hospedes estrangeiros } & \multicolumn{2}{|c|}{ Hóspedes brasileiros } & \multirow{2}{*}{$\begin{array}{l}\text { Total } \\
\text { (mil) }\end{array}$} \\
\hline & (mil) & $(\%)$ & $(\mathrm{mil})$ & $(\%)$ & \\
\hline 1983 & 25 & 20 & 100 & 80 & 125 \\
\hline 1984 & 31 & 23 & 100 & 77 & 1.32 \\
\hline 198.5 & 42 & 24 & 133 & 76 & 175 \\
\hline 1986 & 53 & 22 & 190 & 78 & 243 \\
\hline 1987 & 57 & 28 & 146 & 72 & 203 \\
\hline
\end{tabular}

Os dados da Tabela revelam que a demanda por turismo na cidade de Manaus experimentou um incremento significativo, principalmente considerando-se o fluxo de estrangeiros que passou de $25 \mathrm{mil}$ a 57 mil, mais que dobrando no período de 1983-87.

A demanda externa, na realidade, é ainda maior, pois, seyundo resultados de pesquisa de receptivo, somente cerca de $80 \%$ dos turistas estrangeiros que demandam Manaus instalam-se em estabelecimentos classificados. Desse modo, o número de 57 mil para o ano de 1987 representa, na verdade, mais de 70 mil estrangeiros naquela cidade. 
o perfil dos estrangeiros que visitam o Amazonas, de acordo com as pesquisas realizadas pela Embratur e Emantur, pode ser resumido através das seguintes características básicas:

a) mercado emissor: concentrado na Europa e EUA;

b) permanência média: 4,9 dias;

c) meio de hospedagem : hoteis ( cerca de $80 \%$ );

d) motivo da viagem : passeio ( cerca de $88 \%$ );

e) gasto médio diário per-capita: US\$ 100 (valor médio para 1986).

Quanto à demanda interna, observa-se que esta representa cerca de $70 \%$ do total do fluxo turístico em Manaus, conforme os dados consultados. O principal motivo da demanda é a realização de negócios compras -, embora atualmente se possa admitir que o motivo passeio esteja em crescente alta, em função do turismo ecológico. O perfil do turista brasileiro que viaja para Manaus pode ser assim resumido:

a) mercado emissor: concentrado em São Paulo, Rio de Janeiro e Pará;

b) permanência média: 6,8 dias;

c) meio de hospedagem: hotéis (cerca de $63 \%$ );

d) motivo da viagem : negócios-compras e passeio;

e) gasto médio diário per-capita: US\$ 120 .

\section{IMPACTOS ECONÔMICOS E PERSPECTIVAS DO TURISMO ECOLÓGICO NA AMAZÔNIA}

Utilizando-se os dados de projeção de demanda disponíveis e as informações de oferta e do perfil da demanda, é possível traçar as perspectivas do turismo ecológico, bem como os impactos econômicos diretos que ele pode trazer para a região.

As projeções de oferta e demanda de hospedagem estão apresentadas no Plano Estadual de Turismo do Estado do Amazonas, anteriormente referido. Tais projeções levam em conta as várias categorias de hotéis classificados, assim como o aumento da oferta resultante de projetos que já haviam sido iniciados por ocasião do cálculo. Os dados mostram que as 1.961 unidades habitacionais disponíveis no ano de 1991 estariam, praticamente, todas ocupadas, prevendo-se para o ano de 1992, um déficit de mais de $15 \%$ na oferta da hospedagem.

Este déficit pode representar um sério limitador para a demanda de turismo e para o desenvolvimento do setor na região. Segundo as projeções realizadas pela fonte acima referida, a demanda externa, em 1991, seria da ordem de 92 mil turistas/ano. A demanda interna não foi projetada naquele estudo, mas, para efeito de raciocínio, e tendo em vista sua evolução no passado recente e o prolongarnento da crise da economia brasileira, pode-se, realisticamente, supor que ela esteja situada em torno de 150 mil turistas/ano.

Estes números da demanda são efetivamente maiores, uma vez que dizem respeito somente aos turistas que se hospedam nos estabelecimentos classificados, devendo, portanto, ser corrigidos pelos respectivos coeficientes do meio de hospedagem: $80 \%$ para os estrangeiros e $63 \%$ para os brasileiros. Desse modo, os números reais totalizariam 115 mil no caso dos estrangeiros e 240 mil para os brasileiros.

Para melhor caracterizar a demanda pelo turismo ecológico, os números devem agora ser corrigidos pelos coeficientes da motivação da viagem. O coeficiente de $88 \%$ para o motivo passeio, no caso dos estrangeiros, pode perfeitamente espelhar tal demanda. Já para o caso dos brasileiros, o item predominante negócios-compras encontra-se mesclado ao motivo passeio. Dada à impossibilidade de aqui isolar estas motivações, e para efeito de raciocínio, os cálculos serão realizados utilizando-se duas hipóteses. Na primeira, supondo-se que uma parcela de $50 \%$ estaria exclusivamente motivada pelo turismo ecológico, e, na segunda, efetuando-se o cálculo através da utilização de um coeficiente de $25 \%$ para o motivo passeio dos turistas brasileiros.

A aplicação de tais coeficientes resulta nas seguintes demandas para o turismo ecológico na Amazônia em 1991, mais especificamente para Manaus que é o pólo regional centralizador desta atividade:

a) demanda externa da ordem de 132 mil turistas/ano;

b) demanda interna de 120 mil turistas/ano na primeira hipótese e de 60 mil turistas/ano na segunda hipótese.

Para se chegar à renda diretamente gerada por esta demanda basta utilizar os valores médios de gastos diários e tempo médio de permanência para cada um dos casos, anteriormente especificados na definição do perfil dos turistas. As cifras encontradas são as seguintes:

a) US\$ 64,68 milhões para o turismo ecológico de origem externa;

b) US\$ 97,92 para o turismo ecológico de origem interna na primeira hipótese, e US\$ 48,96 milhões na segunda hipótese.

Estas estimativas referem-se a valores anuais, escolhendo-se como base o ano corrente de 1991. 
É importante salientar que os valores acima calculados para a renda dizem respeito apenas àquela parcela que é diretamente gerada na economia pela atividade do turismo ecológico. Contudo pode-se afirmar que o efeito final será muito maior, uma vez que vários outros efeitos multiplicadores operam na estrutura econômica, segundo os insumos que o setor requisita dos demais e conforme os produtos que ele gera para os outros setores. Assim, o resultado final ainda teria que ser corrigido para maior, ajustando o valor calculado pelo multiplicador setorial do turismo. Ressalte-se, também, que o impacto calculado é um valor mínimo de referência para o conjunto da Amazônia, pois diz respeito apenas aos efeitos diretos que se verificam na cidade de Manaus. O impacto global na região deveria ser calculado levando-se em consideração todas as localidades de turismo na Amazônia, incluindo-se os efeitos diretos e indiretos do turismo na estrutura da economia.

\section{CONCLUSÃO}

Levando-se em conta as caractcrísticas econômicas da região e da atividade em questão, constata-se que a exploração do turismo ecológico na região amazônica apresenta-se como uma excelente alternativa econômica para impulsionar seu crescimento, tendo inclusive, se corretamente explorada, a grande vantagem de não poluir e nem agredir o ecossistema.

O impacto econômico direto na renda da atividade que o turismo ecológico pode potencialmente gerar, tendo como base o ano de 1991, atinge valores anuais da ordem de US\$150 milhões, ou US\$100 milhões de dólares na hipótese inferior. Conforme observado, o impacto total na renia regional é bem mais significativo se forem computados todos os outros efeitos multiplicadores indiretos que ocorrem a partir da injeção inicial.

As particularidades desta alternativa precisam ser melhor exaninadas e, muito embora não se conheça ainda todos as suas implicações, pelo menos o ponto central está bastante claro e sobre o qual há concordância geral: o desenvolvimento do setor de turismo na regiño amazônica, e particularmente do turismo ecológico, é perfeitamente compativel com o crescimento econômico propiciado por um modelo que leva em conta as condicionantes políticas, sociais e ecológicas do desenvolvimento sustentado.

\section{REFERÊNCIAS BIBLIOGRÁFICAS}

MAHAR. D.. Desenvolvimento econômico da Amazônia: uma análise das políticas govermamentais. Rio de Janeiro, IPEA, Relatorio de Pesquisa $\mathrm{n}^{\circ} 3,1978.259$.

BENCHIMOL, S. Amazônia, planetarização e moratória ecológica. São Paulo, CERED. 1989, 141p.

3. MINTER-SUDAM. I Plano de desenvolvimento da Amazônia - Nora República 1986-1989. Belém, 1986,157p.

4. COMUNE, A.E.. Efeitos sócio-econômicos da política de desenvolvimento regional na Amazônia. In: Simpósio "Necessidades, Pesquisas e Estratégias para o Desenvolvimento Auto-Sustentável da Amazônia - Manaus - 1991", Sāo Paulo, UNIP, 1989. Anais. Sáo Paulo, UNIP, 1989.

5. SECRETARIA DA INDÚSTRIA, COMÉRCIO E TURISMO DO ESTADO DO AMAZONAS - EMPRESA AMAZONENSE DE TURISMO-EMAMTUR. Plano estadual de turismo: 1987-1990. Manaus, Diplan, 1987.

6. SECRETARIA DA INDÚSTRIA, COMÉRCIO E TURISMO DO ESTADO DO AMAZONAS. Bolctim de Indicadores Econômicos. Manaus, Agosto/1988. 69p. 